\title{
Prevalence, Knowledge and Self-Reported Containment Practices about Bedbugs in the Resource-Limited Setting of Ethiopia: A Descriptive Cross-Sectional Survey
}

\author{
Kaliyaperumal Karunamoorthi ${ }^{1,2 *}$, Buzuna Beyene', Argaw Ambelu' \\ ${ }^{1}$ Division of Medical Entomology and Vector Control, Department of Environmental Health Science \& \\ Technology, College of Public Health and Medical Sciences, Jimma University, Jimma, Ethiopia \\ ${ }^{2}$ Unit of Tropical Diseases, Faculty of Public Health and Tropical Medicine, Jazan University, Jazan, KSA \\ Email: ${ }^{*}$ karunamoorthi@gmail.com
}

Received 10 May 2015; accepted 19 September 2015; published 22 September 2015

Copyright (C) 2015 by authors and Scientific Research Publishing Inc.

This work is licensed under the Creative Commons Attribution International License (CC BY). http://creativecommons.org/licenses/by/4.0/

(c) (i) Open Access

\begin{abstract}
Over the past decade, a dramatic rise in bedbug resurgence has become one of the top potential public health hazards. This study was conducted to determine prevalence, knowledge and selfreported containment practices about bedbugs in the resource-limited setting of Ethiopia. A community based, cross-sectional survey was conducted between January and May 2014. Selected 260 respondents were interviewed by the administration of a pre-tested questionnaire on knowledge and practices about bedbug infestation in the resource-limited setting of Ethiopia. Overall, 91.6\% (238/260) of the residents had ample awareness on bedbug infestation. The majority of them (97.2\%) extremely bothered about infestations because of bad odors (83.8\%), insomnia (79.8\%), biting (66.9\%), and skin rashes $(56.9 \%)$. A high prevalence of infestation $(72.7 \%)$ was observed. Bedrooms and main hall/salon were identified as potential high-risk areas. Chi-square exhibited a strong association between sanitary status and housing conditions $\left(\chi^{2}=40.91 ; d f=4 ; P\right.$ $=0.0001)$. Besides, there was a strong association between respondents' monthly income $\left(\chi^{2}=\right.$ 42.1; $d f=6 ; \mathrm{P}=0.0001)$ and educational status $\left(\chi^{2}=26.01 ; d f=5 ; \mathrm{P}=0.0001\right.$ ) with the presence or absence of bedbug infestation. Though the majority of respondents had adequate knowledge, they suffer with deprived practices attributable to deficient resources as well as negligence/ignorance. This study emphasizes the following key interventions: 1) community-based awareness campaigns, 2) implementation of sustainable preventive/containment strategies, 3) educational interventions to ensure translation of knowledge into practices, and 4) the implementation of appropriate poverty alleviation programs to enhance the local-residents living-standard in the future.
\end{abstract}

*Corresponding author.

How to cite this paper: Karunamoorthi, K., Beyene, B. and Ambelu, A. (2015) Prevalence, Knowledge and Self-Reported Containment Practices about Bed Bugs in the Resource-Limited Setting of Ethiopia: A Descriptive Cross-Sectional Survey. Health, 7, 1142-1157. http://dx.doi.org/10.4236/health.2015.79130 


\section{Keywords}

\section{Bedbug, Bedbug Infestation, Containment and Management Practices, Ethiopia}

\section{Introduction}

Bedbugs are wingless hematophagous ectoparasites. The common bedbug, Cimex lectularius L., the tropical bedbug, C. hemipterus (Fabricius), and a few closely related species of blood-feeding true bugs (Hemiptera: Cimicidae) have been the persistent pests of humans throughout recorded history [1]. While in the absence of humans, they may feed on mice, rats, chicken and other animals [2]. Usinger (1966) [3] suggested that the ancestors of bedbugs fed on cave-dwelling bats and accordingly our ancestors became an alternative host when they shared caves with bats. Subsequently, they evolved parallel to the social evolution of the human species.

In the past decade, there is a dramatic resurgence of bedbug infestation which has been observed worldwide, both in the high-income economies viz., the United States, Canada, Europe, Australia, as well as among some of the low-income African and Asian countries [4]. It is fuelled by the unplanned urbanization, uncontrolled population spurt, poor personal hygiene, inadequate resources, unawareness, enhanced international travel, widespread insecticide resistance, and poor-quality housings [5] [6]. The infestation has been detected across a wide range of settings regardless of their hygienic status like single family homes, multi-unit dwellings, buses, trains, cruise ships, aircraft, hotels, schools, cinema halls, shelters, dorm rooms, and health facilities [7] [8].

Bedbugs' classic hiding niches include cracks and crevices of beds, wooden furniture, couch or sofa, floors, walls, mattress, and/or curtains [2]. During the night, they emerge and migrate up to 20 feet to feed (bite) on their preferred host, humans. They sense and seek their hosts through the perception of body heat, odor and by detection of carbon dioxide $\left(\mathrm{CO}_{2}\right)$. They recurrently feed on humans to complete their life cycle. After feeding, they defecate and leave black or brown spots, the typical signs of bedbug infestation [9]. Although bedbugs are not in as insect vector of diseases, they reduce the quality of life by causing discomfort, anxiety, insomnia, ostracism, psychological disorders or various phobias [2] [10]. The victims have often been reported to suffer from biting and a variety of cutaneous and systemic reactions [10] [11]. At the moment, elimination of the infestation is one of the Herculean tasks as emergence of resistance to pyrethroid insecticides [12]. Irrespective of their socioeconomic status, all sections of the society are at the risk of being bitten. Therefore, bedbugs have proven to be a challenging pest and so it becomes the subject of significant research and public concern.

Bedbug infestation is a quite common phenomenon in the resource-limited settings as it is inextricably linked to poverty. In Ethiopia, it is one of the most neglected, under-reported as well as under-studied health care concerns owing to the massive disease burden of the major killer diseases viz. Tuberculosis, HIV/AIDS and Malaria. In Ethiopia nearly $80 \%$ of the population is living in the remote rural areas with substandard housing, which imposes a severe risk to the infestation. Nevertheless, the prevalence of bedbug infestation and its public health impacts remains little-known. Besides, the information on communities' knowledge and containment practices is also quite dearth and scanty. This could lead to a serious setback to the ongoing and future effective bedbug interventions in the long term.

In this context, it is an attempt to identify potential risk indicators of bedbug infestation and control practices in an Ethiopian resource-poor setting. It could provide an opportunity to all pertinent stakeholders to recognize the bedbug infestation as a matter of public health and medical concern/nuisance. It may pave the way to detect, prevent, and control infestations by the cost-effective sustainable management/containment strategies. Besides, it could be helpful to develop the next generation tools for the bedbug resurgence surveillance, monitoring, management and control in the future.

\section{Materials and Methods}

\subsection{Description of the Survey Setting}

The survey was conducted among the Amuru town residents and it is the district [Woreda (an administrative body)] next to the village [Kebele (small administrative unit)]. It is located North West of Horo-Guduru Wollega 
Zone, Oromia region, Ethiopia (Figure 1). It is located at nearly $320 \mathrm{~km}$ North West of Addis Ababa, the federal capital city of Ethiopia. It is situated at an altitude of $760-2505 \mathrm{~m}$ above the sea level and the average annual rainfall and temperature are about $800-1500 \mathrm{~mm}$ and 180C, respectively. Based on climatic conditions, the present study area classified is as one of the woienadega areas of Ethiopia. Local residents cultivate Teff (Eragrostis tef Zucc.), maize (Zea mays L.), barley (Hordeum vulgare L.), cereal such as sorghum (Sorghum bicolor L.), and wheat (Triticum aestivum L.). Besides, it is also well-known for the cultivation of the cash crop like khat (Catha edulis Forsk.) and coffee (Coffea arabica L.) and raising live stocks.

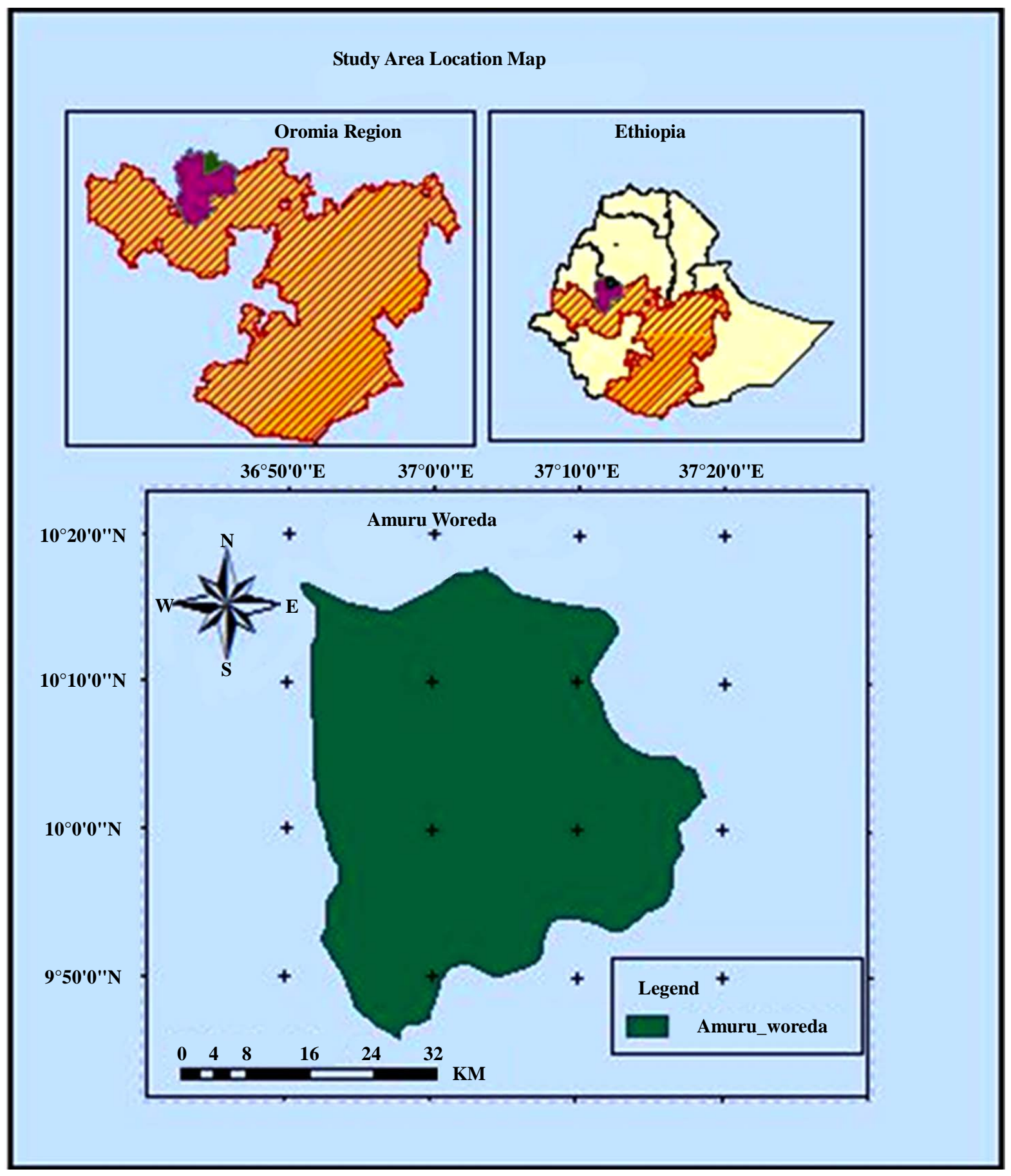

Figure 1. Location of the study area Amuru town, Wollega zone, Oromia region, Ethiopia. 


\subsection{Study Design and Sampling Technique}

The study was a community based cross-sectional survey conducted between January and May of 2014. A stratified, systematic random sampling was used for selection of a total of 260 households from all the total existing 1164 households. The sample size was calculated by employing 95\% confidence interval formula to estimate a population proportion.

\subsection{Interview}

The interview was conducted by involving 260 eligible study participants. To improve the quality of the data, pre-testing of the questionnaire was carried out prior to the authentic data collection. The questionnaire was tested on ten percent of the respondents by the enumerators, in an area different from the study area, but with the similar socio-demographic pattern. One adult from each selected household was interviewed about the bedbug's infestation knowledge, infestation and control practices by administering a pretested questionnaire. Male and female respondents from all age-groups were included. To avoid biased information and variables, the structured questionnaire has been prepared in the English language and has been translated into the local native language (Afan Oromo) in order to make it easy to understand and to administer by interviewers and interviewees. In addition, the researchers were trained in determining the different levels of infestation. Subsequently they made the physical personal inspection to evaluate the housing conditions and the degree of bedbug infestation in the chosen households by using the standard observational checklists [Appendix].

Before the commencement of the survey, meetings with community health workers, community leaders and members of the neighborhood associations were organized in which the objectives of the survey were clearly explained. Since all the selected respondents were above eighteen-years of age, the informed written consent was obtained from each of the study participants prior to the interview, with the help of an approved voluntary consent form. Every participant was assured to withdraw the interview at any phase if they wish to do so. However, all the informants actively participated and no one declined to cease the interview. Study identification numbers were used instead of participant names and the information collected has been kept confidential. Feedback to the study population was conducted in the form of dissemination meetings after the completion of the survey.

\subsection{Data Collection}

A team of well-trained and closely supervised local interviewers conducted the household survey using a pretested questionnaire to interview with the representative of the selected household. Interviewers collected information regarding socio-demographic and physical observation and inspection on bedbug infestation and prevalence data. The chosen respondents were invited and called upon to impart their knowledge, attitude and control practices. The main questions focused on 1) the knowledge on bedbugs, 2) bedbugs' infestation as a matter of public health concern/issue, 3) diverse health impact (psychological, allergic, and clinical presentation), 4) types of interventions practiced, and 5) name of the local plants used against bedbugs.

Additionally, the prevalence of bedbug infestation was also determined by the personal physical inspections (using suggestive key indicators like the presence of adults, nymphs, eggs, and faeces or traces of blood from crushed bedbugs) and by using the standard checklists. The surveyed households were categorized into three groups, poor, fair and good based on a classification scheme that mainly considers the housing quality (careful inspection of mattresses/fabrics and other household items like bed), and domestic and personal hygiene for the infestation. The investigators also physically removed the adults and large nymphs using forceps during the inspections. Residents were advised to decontaminate their infested materials and proper health education was offered to each respondent to minimize the infestation.

\subsection{Data Management and Analysis}

In the field, data were collected in a standardized questionnaire and data collection forms and was checked for errors and completeness. Data was then counterchecked before entry into DbaseV (Borland International, Scotts Valley, California, USA) using the double entry system. Summary statistics were being performed using STATA version 10 (STATA Corp., Texas, USA). The range and mean were analysed and appropriate tables, graphs and percentage details were displayed. A Chi-square analysis was performed to test the hypothesis. The 
level of significance was also determined by using 95\% of confidence intervals and P-value.

\section{Results}

\subsection{Socio-Demographic Characteristics of Survey Respondents}

The socio-demographic characteristics of the study participants are shown in the Table 1 . It has been estimated that nearly $91.6 \%(238 / 260)$ of the respondents had ample awareness of bedbug infestation and control (Table 1). Overall, 68.6\% (179/260) and 31.4\% (82/260) of the respondents had knowingly on the mode of growth/ development and the rest didn't.

Table 1. Study of respondents with gender, age, ethnicity, educational status, average monthly income and knowledge of bedbug infestation and control practices in Ethiopia.

\begin{tabular}{|c|c|c|}
\hline Socio-demographic variables & $\mathbf{n}$ & $\%$ \\
\hline \multicolumn{3}{|l|}{ Gender } \\
\hline Male & 164 & 63.1 \\
\hline Female & 96 & 36.9 \\
\hline \multicolumn{3}{|l|}{ Age in years } \\
\hline $18-20$ & 70 & 26.9 \\
\hline $21-30$ & 36 & 13.9 \\
\hline $31-40$ & 33 & 12.7 \\
\hline $41-50$ & 36 & 13.8 \\
\hline $51-60$ & 21 & 08.1 \\
\hline$>60$ & 63 & 24.3 \\
\hline \multicolumn{3}{|l|}{ Educational status } \\
\hline Illiterate & 18 & 06.9 \\
\hline Can read and write & 29 & 11.2 \\
\hline $1-5^{\text {th }}$ grade & 39 & 15.1 \\
\hline $6-10^{\text {th }}$ grade & 55 & 21.2 \\
\hline $11-12^{\text {th }}$ grade & 36 & 13.9 \\
\hline Above $12^{\text {th }}$ grade & 83 & 31.9 \\
\hline \multicolumn{3}{|l|}{ Monthly income [Ethiopian Birr (1 USD = 18.78 Eth Birr)] } \\
\hline$<500$ & 57 & 21.9 \\
\hline $501-1000$ & 70 & 26.9 \\
\hline $1001-1500$ & 55 & 21.2 \\
\hline $1501-2000$ & 37 & 14.3 \\
\hline $2001-2500$ & 31 & 11.9 \\
\hline $2501-3000$ & 05 & 02.0 \\
\hline$>3000$ & 05 & 02.0 \\
\hline \multicolumn{3}{|c|}{ Do you have awareness on bedbugs' infestation and control? } \\
\hline Yes & 23 & 91.6 \\
\hline No & 22 & 08.4 \\
\hline
\end{tabular}




\subsection{Housing Conditions and Bedbug Infestation}

Out of 260 houses 177 (68.1\%) were privately owned and 83 (31.9\%) were rented by the individuals/municipality. Overall, 172 (66.2\%) and 81 (31.2\%) of the houses were built of mud and cement, respectively. Almost, 200 (76.9\%) and 50 (19.3\%) houses were with bare soil floors, and the concrete, respectively. Pertaining the type of the roof, 237 (91.2\%), 13 (5.1\%) and 10 (3.7\%) houses were constructed with the corrugated iron sheet (CIS), thatched, and a few of them with the materials like plastic sheets and tarpaulins, respectively. The investigators also made a visual personal inspection of the potential high-risk sleeping areas (rooms), cloth, and other hiding niches in order to estimate the prevalence of infestation (Table 2) and found that overall 72.7\% (189/260) of the households were infested. The chi-square analysis exhibits a strong association between sanitary status and housing conditions $\left(\chi^{2}=40.91 ; d f=4 ; \mathrm{P}=0.0001\right)$ (Table 2).

Both the bedrooms and main hall/salon were identified as potential risk-areas in terms of infestation (Figure 2). Nearly $97.2 \%$ (203/209) of the respondents were extremely concerned about the infestation due to various negative consequences, particularly bad-odour (83.8\%), biting (66.9\%), and social stigma (42\%) (Figure 3).

\subsection{Bedbug Management and Control Practices}

The residents were noted to apply various bedbug interventions, particularly plant-based products as repellent by means of conventional intervention. Overall, 89.3\% (232/260) and 83.9\% (218/260) of the respondents were found to use Endod (Phytolacca dodecantra L’Hér.), and Tid (Juniperus procera L.) leaves solutions (suspensions) as repellant (Table 3). Besides, study participants were also applying a various environmental and chemical control interventions (Table 3). About, 81.2\% (211/260) and 91.2\% (237/260) of the respondents have

Table 2. Classification of the housing conditions based on the sanitary conditions with reference to bedbugs' infestation.

\begin{tabular}{|c|c|c|c|c|c|c|c|c|}
\hline \multirow{2}{*}{ S. No. } & \multirow{2}{*}{ Sanitary conditions } & \multicolumn{2}{|c|}{ Good } & \multicolumn{2}{|c|}{ Fair } & \multicolumn{2}{|c|}{ Poor } & \multirow{2}{*}{ P-value } \\
\hline & & $\mathrm{n}$ & $\%$ & $\mathrm{n}$ & $\%$ & $\mathrm{n}$ & $\%$ & \\
\hline 1. & Personal hygiene & 43 & 16.6 & 106 & 40.8 & 101 & 38.9 & $\chi^{2}=40.91$ \\
\hline 2. & Good-housing conditions & 92 & 35.4 & 101 & 38.9 & 67 & 25.8 & $d f=4$ \\
\hline 3. & Environmental sanitation & 97 & 37.4 & 111 & 42.6 & 52 & 20.1 & $\mathrm{P}=0.0001^{*}$ \\
\hline
\end{tabular}

Note: ${ }^{*} \mathrm{P}<0.05$ statistically significant.

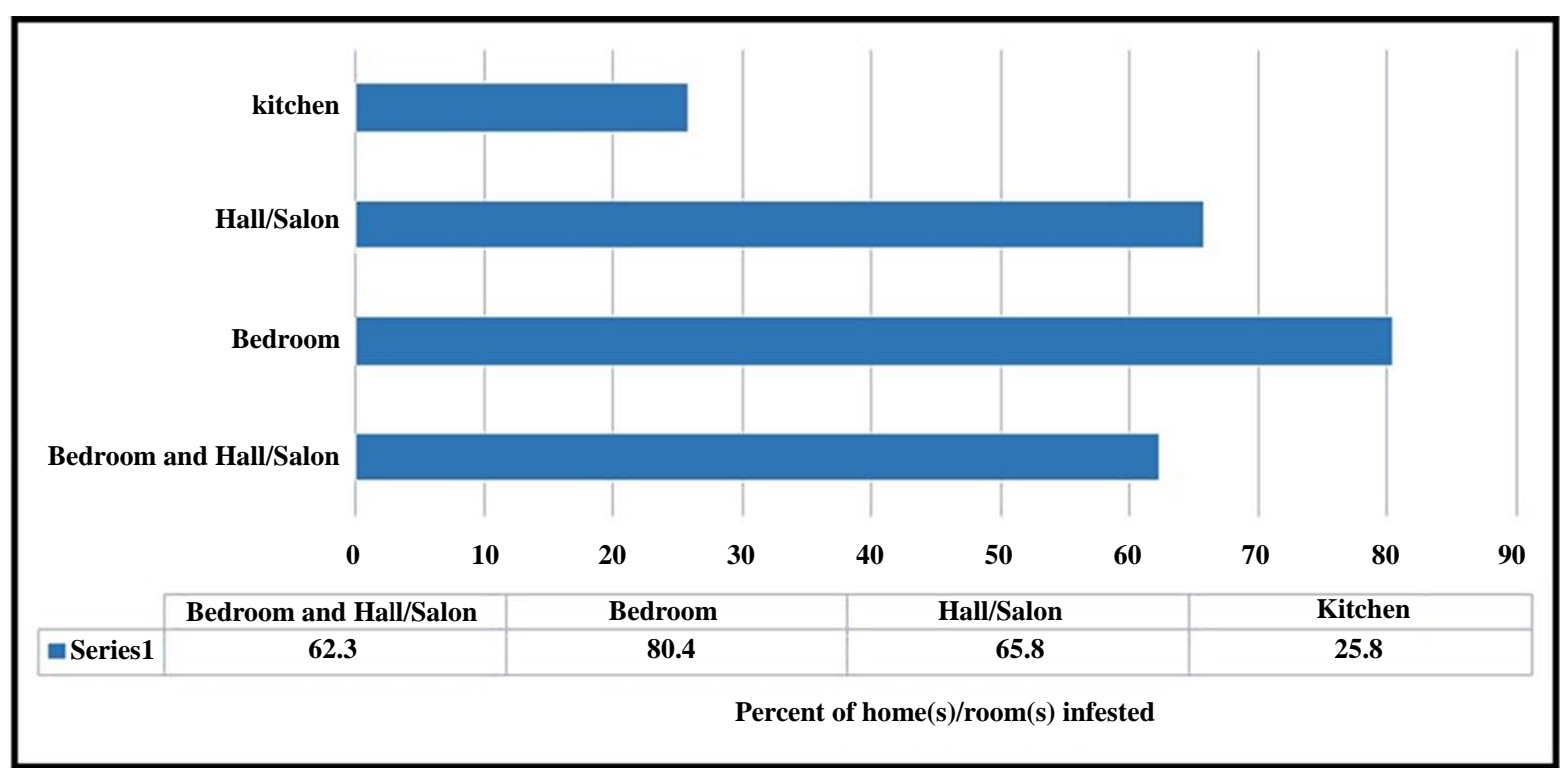

Figure 2. The prevalence of infestation in the whole houses and partition room(s). Note: a percent does not add up to 100 , because of multiple responses. 


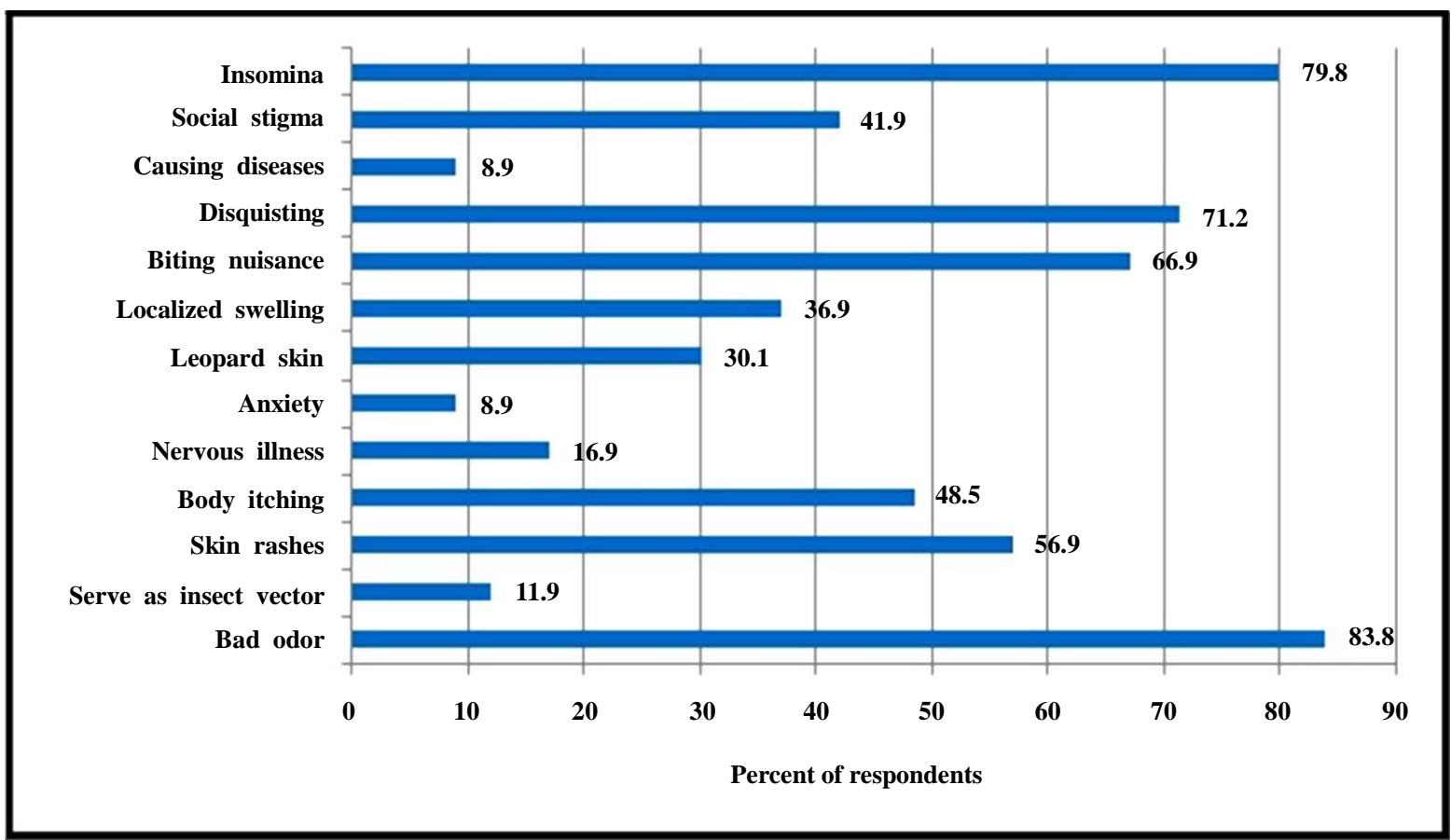

Figure 3. Respondents' perception on the physico-psycho-socio-health impacts of bedbug infestation. Note: a percent does not add up to 100 , because of multiple responses.

Table 3. Respondents of various self-reported practices for the bedbug prevention and control.

\begin{tabular}{|c|c|c|c|}
\hline \multicolumn{2}{|r|}{ I. Conventional Interventions as bedbug repellent } & \multirow{2}{*}{$\begin{array}{c}\mathrm{n} \\
201\end{array}$} & \multirow{2}{*}{$\begin{array}{c}\text { Percent }^{\mathrm{a}} \\
77.4\end{array}$} \\
\hline 1. & Leaves of Eucalyptus (Eucalyptus citriodora Hook.) solution/dried leaves as fumigant & & \\
\hline 2. & Keberacho (Echinops kebericho Mesfin.) plants' dried roots as fumigant & 198 & 76.2 \\
\hline 3. & Tid (Juniperus procera L.) leaves suspension & 218 & 83.9 \\
\hline 4. & Endod (Phytolacca dodecantra L’Hér.) leaves solution & 232 & 89.3 \\
\hline 5. & Other plants' materials/products & 014 & 05.4 \\
\hline \multicolumn{4}{|c|}{ II. Environmental Interventions } \\
\hline 1. & Personal hygiene & 141 & 54.3 \\
\hline 2. & Washing the infested clothes frequently & 149 & 57.4 \\
\hline 3. & Proper disposal of domestic waste & 237 & 91.2 \\
\hline 4. & Plastering of wall cracks and crevices & 211 & 81.2 \\
\hline 5. & Pouring boiled water on the infested areas/materials & 109 & 42.1 \\
\hline 6. & Others & 021 & 08.1 \\
\hline \multicolumn{4}{|c|}{ III. Chemical Interventions } \\
\hline 1. & $5 \% \mathrm{DDT}$ & 154 & 59.3 \\
\hline 2. & Commercial insecticide products/Roach killer & 174 & 66.9 \\
\hline 3. & Pyrethroid-based insecticides & 102 & 39.3 \\
\hline 4. & Other pesticides & 017 & 06.6 \\
\hline
\end{tabular}

Note: a percent does not add up to 100, because of multiple responses. 
repaired the cracks and crevices in the walls/ceiling by plastering and properly discarding their household waste, respectively (Table 3). In addition, 66.9\% (174/260) and 59.3\% (154/260) of the people applying several commercial insecticide products like Roach Killer [brand name of pesticide spray; (which is extensively available in the Ethiopian markets)] and 5\% DDT (dichloro-diphenyl-trichloroethane) dustable powder to prevent/curb bedbugs (Table 3). Overall, 72.7\% (189/260) of the houses were found to be infested whereas just $27.3 \%$ (71/260) of them were uninfestated (Table 4). Chi-square analysis exhibited a strong association between respondents' monthly income $\left(\chi^{2}=42.1 ; d f=6\right.$; P-value $\left.=0.0001\right)$, and educational status $\left(\chi^{2}=26.01 ; d f=5\right.$; P-value $=$ 0.0001 ) with the presence or absence of bedbug infestation (Table 4).

\section{Discussion}

Indeed, bedbugs are ecto-parasitic insects and they have been taken into account as one of the potential medical and public health hazards. Fairly large numbers of studies have been reported on various aspects of bedbug; however, to the best of our knowledge, no study to date has focused on the communities' awareness and bedbug control practices. Generally, knowledge, attitude and practice (KAP) studies are considered to be an educational diagnosis on the risk-population. They often aid to design tailored strategies suitable for the local socio-cultural and political contexts of at-risk communities [13]. In this context, this paper is aimed to identify potential key risk indicators associated with the bedbug infestation. Compounding factors like poverty, limited-resources and negligence or ignorance often cause the sustainable bedbug interventions out of reach.

The majority of informants (91.6\%) had ample awareness of bedbug infestation and control (Table 1). The level of awareness was noted to be extremely higher than the previous study and it has been reported to be terribly lower in awareness [14] among the developed countries. This could be possibly explained that this is because the survey has been conducted in one of the resource-poor settings like Ethiopia, where poverty and unhygienic living conditions are quite widespread. Besides, many poverty interrelated issues often inflame the higher-level of infestation and the associated public health and medical risks in Ethiopia. Therefore, local residents

Table 4. The association between respondent's monthly income and educational status with presence or absence of bedbugs' infestation.

\begin{tabular}{|c|c|c|c|c|}
\hline \multirow{2}{*}{ Variables } & \multicolumn{3}{|c|}{ Number of Bedbugs } & \multirow{2}{*}{ P-value } \\
\hline & Total & Presence & Absence & \\
\hline \multicolumn{5}{|c|}{ Educational status } \\
\hline Illiterate & 18 & 10 & 08 & \\
\hline Read and write & 29 & 22 & 07 & $\chi^{2}=26.01$ \\
\hline $1-5^{\text {th }}$ grade & 39 & 23 & 16 & $d f=5$ \\
\hline $6-10^{\text {th }}$ grade & 55 & 33 & 22 & $\mathrm{P}=0.0001^{*}$ \\
\hline $11-12^{\text {th }}$ grade & 36 & 25 & 11 & \\
\hline $12+$ & 83 & 76 & 07 & \\
\hline \multicolumn{5}{|c|}{ Monthly income [Ethiopian Birr (1 USD = 18.78 Eth Birr)] } \\
\hline$<500$ & 57 & 44 & 13 & \\
\hline $501-1000$ & 70 & 36 & 34 & \\
\hline $1001-1500$ & 55 & 34 & 21 & \\
\hline $1501-2000$ & 37 & 43 & 03 & $\chi 2=42.1$ \\
\hline $2001-2500$ & 31 & 31 & 00 & $d f=6$ \\
\hline $2501-3000$ & 05 & 05 & 00 & $\mathrm{P}=0.0001^{*}$ \\
\hline$>3000$ & 05 & 05 & 00 & \\
\hline
\end{tabular}

Note: ${ }^{*} \mathrm{P}<0.05$ statistically significant. 
might have acquired ample awareness by means of long-period of exposure/personal contact (bite). A study reported that nearly sevenfold higher number of people identified bedbugs rightly if they have had prior contact with bedbugs than those who had not [14].

The respondents have received bedbug related information from several sources via cultural knowledge transmission (i.e. word of mouth) from their parents/relatives (73.1\%), previous experience (contact) (14.3\%), health facilities (7.8\%), and educational institutions/mass media (4.8\%). The finding is concurrent with a very recent study conducted in Germany by Seidel and Reinhardt (2013) [14] reporting on; (a) the previous contacts with bed bugs (60\%), (b) knowledge from friends or relatives (25\%), and (c) school or education courses (15\%). It has also been reported that the previous experience has contributed to the correct identification of bedbug. Therefore, showing the bedbugs to the people could be helpful to improve the awareness of the people [14]. It is important to note that the higher-level of awareness is one of the important social determinants of health and it can make a significant contribution to public health promotion campaigns against bedbug. Henceforth it shall often offer an ideal opportunity for us to implement sustainable community-based interventions by generating awareness in this vicinity.

In spite of the limited-resources, relatively sizable numbers of households were categorized to be good (free of infestation). However, most of the houses were poorly maintained by the residents (Table 2). In the developing economies, delivering quality healthcare services to all the needy peoples is a quite challenging task because of inadequate healthcare facilities, inadequate skilled personnel, and underfunding. However, the findings exhibit that leading a healthy life is relatively feasible by improving the domestic and personal hygiene of the society. These can be achieved by aggressive health education campaigns to translate their knowledge into practice to lead a healthier life. Subsequently, it can lead to attaining our ambitious Millennium Development Goals (MDGs) in the near future.

Overall, 80.4\% (152/189) of the bedrooms, followed by 65.6\% (124/189) of main hall/salon were observed to be infested (Figure 2), and they are the most potential risk-associated rooms or areas in the households. Since bedbugs hide in the cracks and crevices of walls and other materials like bed, chairs and couches, they emerge and get easy access to feed (bite) on the human at night. 15 If family size is quite bigger, all the family members cannot accommodate in the bedroom, rather some of them might prefer to sleep in the salon/main hall. These create an ideal situation for the infestation; consequently the bedrooms and salons are often infested than in any other rooms (Figure 1). Bedbugs are nocturnal feeders and will aggregate together in harbourages in close proximity to where their preferred host sleeps [15].

Due to the recent resurgence, it is extremely vital to understand the potential health risks associated with bedbug infestation [11]. The great majority of the respondents were worried because of a various adverse psycho-socio-economic-health consequences of infestation (Figure 2). A recent study reported that bedbug infestation causes serious social stigmatization and isolation too [16]. The majority of people consider that the persons with poor hygiene and low economic status might have infested [3]. Though bedbug bites are painless, it may cause severe reactions ranging from asymptomatic to itchy, swollen and blistered bites on exposed skin, sometimes resulting in secondary bacterial infections too [17].

Considerable numbers of respondents erroneously perceived that bedbug may cause several diseases and they can serve as insect vectors too (Figure 3). To date there are no scientific report that bedbugs can transmit the infections [17] [18], however, there are several studies indicate that they can cause severe skin irritations [19], stronger dermatological responses [20], and psychological stress [21]. Bedbugs are classified as urban pests and as a potential health hazard [4]. The infestation is quite unbearable in the hotel industry as it often tarnishes the hotel's reputations consequently cause serious negative economic consequences [14].

Since the pre-historic era the people tend to use various plants to either repel or to kill various dreadful bloodsucking insects. Even today it is one of the quite common phenomena in the resource-limited African settings like Ethiopia [22]. Respondents apply several plants as repellent to prevent/manage and control the infestation. The local-residents use the Endod, Tid, and Eucalyptus (Eucalyptus citriodora Hook.) leaves' solutions (suspensions) as repellant (Table 3). Besides, the dried leaves of Eucalyptus and the roots of Keberacho (Echinops kebericho Mesfin.) are also applied as fumigants. In Ethiopia, several previous studies reported that these plants can serve as potential repellents against mosquitoes and several other domestic pests [23]-[25]. In resource-limited settings, it could be one of the most viable options (strategies) to curb infestation efficiently, since these plants are easily accessible, affordable, locally known, and culturally acceptable [26]. However, further scientific analyses are also required to be warranted to isolate and to identify the responsible bio-active mo- 
lecules as well as to establish their mammalian toxicity too [27].

Residents were practicing various environmental interventions like plastered the cracks and crevices of walls/ceiling to eliminate the hiding niches of bedbugs, while a few of them frequently exposed their infested materials/cloths under sunlight to inhibit infestation (Table 3). The great majority of the respondents has been using a variety of chemicals, particularly Roach Killer spray/fumigant and 5\% of DDT powder (Table 3) to repel or to kill various domestic pests like cockroach, housefly, mosquitoes particularly to curb the bedbug infestation. Indeed insecticides are powerful weapons in the fight against insect vector of diseases and domestic pests. However, the haphazard and unsafe insecticide application could inflict serious negative impacts on human health, animals and the environment [28] [29]. Since insecticides are toxic in nature appropriate awareness campaigns instructing a safe use of insecticide is quite inevitable [29]. In 1950, the DDT was very effective to control the bedbugs [30], subsequently the liberal use of DDT, and changes in cultural practices had eradicated the infestations in the developed world [31]. Today, pyrethroids are one of the most commonly used insecticides to combat the bedbug infestations. However, bedbugs have developed resistance to several insecticides, including pyrethroids [30] [32] and other insecticides like malathion, diazinon, lindane, chlordane, and dichlorvos too. The recent worldwide bedbug resurgence is mainly attributable to the widespread insecticide resistance, particularly pyrethroids [30].

Chi-square analysis showed a strong association between respondents' monthly income and educational status with the presence or absence of bedbug infestation and it was statistically significant (Table 4) $(\mathrm{P}=0.0001)$. Though the infestation cuts all the socio-economic-barriers, perhaps it is quite obvious that the economically-disadvantaged people disproportionably share a larger burden of infestation than wealthier people. The experience of a bedbug infestation of low-income people poses a significant threat to their overall health [16]. It could be possibly explained that the educated individuals are expected to have more awareness than the illiterates and it could directly reduce the degree of infestation in their homes. Therefore, it is essential for healthcare/educational institutions and national, regional and local responsible bodies to recognize the risk of infestation and the need for the development of protocols to prevent, identify, and generate awareness, and to eliminate the infestation effectively [33].

\section{Conclusion}

Indeed bedbugs are considered to be one of the potential medical and public health hazards in resource-constrained settings like Ethiopia. Poor quality of housing, overcrowding and other related confounding factors serve as a potential breeding ground for widespread bedbug infestation. However, it can be effectively contained with the help of the existing resources if the people are properly educated to translate their knowledge into practices. Therefore, this study calls for the following key interventions for the sustainable bedbug elimination that includes: 1) community-based awareness campaigns, 2) implementation of sustainable preventive/containment strategies, 3) educational interventions via mass media, 4) continuous monitoring and quality assurance mechanisms to be placed to ensure zero tolerance of infestation. Furthermore, implementation of suitable poverty alleviation programmes could substantially enrich the living-standard of the people in the future.

\section{Acknowledgements}

We are very much grateful to the study participants who shared their knowledge on the Bedbugs infestation. Without their contribution, this study would have been impossible. The authors would like to acknowledge Ms. L. Melita for her sincere assistance in editing the manuscript. Our last but not least heartfelt thanks go to our colleagues from the School of Environmental Health Science, Faculty of Public Health, Jimma University, Jimma, Ethiopia, for their kind support and cooperation.

\section{References}

[1] AFPMB (Armed Forces Pest Management Board) (2013) Bed Bugs-Importance, Biology, and Control Strategies. Technical Guide No. 44. http://www.afpmb.org/sites/default/files/pubs/techguides/tg44.pdf

[2] Hwang, S.W., Svoboda, T.J., De Jong, I.J., Kabasele, K.J. and Gogosis, E. (2005) Bed Bug Infestations in an Urban Environment. Emerging Infectious Diseases, 11, 533-538. http://dx.doi.org/10.3201/eid1104.041126

[3] Usinger, R.L. (1996) Monograph of Cimicidae (Hemiptera-Heteroptera). Thomas Say Foundation, College Park.

[4] Harlan, H.J., Faulde, M.K. and Baumann, G.J. (2008) Bedbugs. In: Bonnefoy, X., Kampen, H. and Sweeney, K., Eds., 
Public Health Significance of Urban Pests, World Health Organization, Regional Office for Europe, Copenhagen, 131154.

[5] Panagiotakopulu, E. and Buckland, P.C. (1999) Cimex lectularius L., the Common Bedbug from Pharaonic Egypt. Antiquity, 73, 908-911.

[6] Potter, M.F. (2008) The History of Bed Bug Management. Bed Bug Supplement: Lessons from the Past. Pest Control Technology, 36, 12.

[7] Wang, C., Saltzmann, K., Chin, E., Bennett, G.W. and Gibb, T. (2010) Characteristics of Cimex lectularius (Hemiptera: Cimicidae), Infestation and Dispersal in a High-Rise Apartment Building. Journal of Economic Entomology, 103, 172177. http://dx.doi.org/10.1603/EC09230

[8] Delaunay, P. (2012) Human Travel and Traveling Bedbugs. Journal of Travel Medicine, 19, 373-379. http://dx.doi.org/10.1111/j.1708-8305.2012.00653.x

[9] Wang, C. (2009) Bed Bugs. The State University of New Jersey, Rutgers, Fact Sheet FS1098.

[10] Goddard, J. and deShazo, R. (2012) Psychological Effects of Bed Bug Attacks (Cimex lectularius L.). American Journal of Medicine, 125, 101-103. http://dx.doi.org/10.1016/j.amjmed.2011.08.010

[11] Paul, J. and Bates, J. (2000) Is Infestation with the Common Bedbug Increasing? British Medical Journal, 320, 1141. http://dx.doi.org/10.1136/bmj.320.7242.1141

[12] Romero, A. (2009) Biology and Management of the Bed Bug, Cimex lectularius L. (Heteroptera: Cimicidae). Doctoral Dissertations, University of Kentucky, Lexington.

[13] Chinnakali, P., Gurnani, N., Upadhyay, R.P., Parmar, K., Suri, T.M. and Yadav, K. (2012) High Level of Awareness but Poor Practices regarding Dengue Fever Control: A Cross-Sectional Study from North India. North American Journal of Medical Sciences, 4, 278-82. http://dx.doi.org/10.4103/1947-2714.97210

[14] Seidel, C. and Reinhardt, K. (2013) Bugging Forecast: Unknown, Disliked, Occasionally Intimate. Bed Bugs in Germany Meet Unprepared People. PLoS ONE, 8, e51083. http://dx.doi.org/10.1371/journal.pone.0051083

[15] Gangloff-Kaufmann, J., Hollingsworth, C., Hahn, J., Hansen, L., Kard, B. and Waldvogel, M. (2006) Bed Bugs in America: A Pest Management Industry Survey. American Entomologist, 52, 105-106. http://dx.doi.org/10.1093/ae/52.2.105

[16] Lyons, J. (2010) The Social Impacts of Bed Bugs on Inner Winnipeg. University of Manitoba, Manitoba.

[17] Goddard, J. (2009) Bed Bugs (Cimex lectularius) and Clinical Consequences of Their Bites. Journal of American Medical Association, 301, 1358-1366. http://dx.doi.org/10.1001/jama.2009.405

[18] Doggett, S.L., Dwyer, D.E., Penas, P.F. and Russell, R.C. (2012) Bed Bugs: Clinical Relevance and Control Options. Clinical Microbiology Review, 25, 164-192. http://dx.doi.org/10.1128/CMR.05015-11

[19] Reinhardt, K., Kempke, D., Naylor, R. and Siva-Jothy, M.T. (2009) Sensitivity to Bedbug Bites, Cimex lectularius. Medical and Veterinary Entomology, 23, 163-166. http://dx.doi.org/10.1111/j.1365-2915.2008.00793.x

[20] Leverkus, M., Jochim, R.C., Schäd, S., Bröcker, E.B. and Andersen, J.F. (2006) Bullous Allergic Hypersensitivity to Bed Bug Bites Mediated by IgE against Salivary Nitrophorin. Journal of Investigative Dermatology, 126, 91-96. http://dx.doi.org/10.1038/sj.jid.5700012

[21] Goddard, J. and de Shazo, R. (2012) Psychological Effects of Bedbug Attacks (Cimex lectularius L.). American Journal of Medicine, 125, 101-103. http://dx.doi.org/10.1016/j.amjmed.2011.08.010

[22] Karunamoorthi, K., Mulelam, A. and Wassie, F. (2008) Laboratory Evaluation of Traditional Insect/Mosquito Repellent Plants against Anopheles arabiensis, the Predominant Malaria Vector in Ethiopia. Parasitology Research, 103, 529-534. http://dx.doi.org/10.1007/s00436-008-1001-9

[23] Karunamoorthi, K., Mulelam, A. and Wassie, F. (2009) Assessment of Knowledge and Usage Custom of Traditional Insect/Mosquito Repellent Plants in Addis Zemen Town, South Gonder, North Western Ethiopia. Journal of Ethnopharmacology, 121, 49-53. http://dx.doi.org/10.1016/j.jep.2008.09.027

[24] Karunamoorthi, K., Ilango, K. and Endale, A. (2009) Ethnobotanical Survey of Knowledge and Usage Custom of Traditional Insect/Mosquito Repellent Plants among the Ethiopian Oromo Ethnic Group. Journal of Ethnopharmacology, 125, 224-229. http://dx.doi.org/10.1016/j.jep.2009.07.008

[25] Karunamoorthi, K. and Tsehaye, E. (2012) Ethnomedicinal Knowledge, Belief and Self-Reported Practice of Local Inhabitants on Traditional Antimalarial Plants and Phytotherapy. Journal of Ethnopharmacology, 141, 143-150. http://dx.doi.org/10.1016/j.jep.2012.02.012

[26] Karunamoorthi, K., Ramanujam, S. and Rathinasamy, R. (2008) Evaluation of Leaf Extracts of Vitex negundo L. (Family: Verbenaceae) against Larvae of Culex tritaeniorhynchus and Repellent Activity on Adult Vector Mosquitoes. Parasitology Research, 103, 545-550. http://dx.doi.org/10.1007/s00436-008-1005-5 
[27] Karunamoorthi, K. (2012) Plant-Based Insect Repellents: Is That a Sustainable Option to Curb the Malaria Burden in Africa? Journal of Medicinal and Aromatic Plants, 1, e106.

[28] Karunamoorthi, K., Mohammed, M. and Wassie, F. (2012) Knowledge and Practices of Farmers with Reference to Pesticide Management: Implications on Human Health. Achieves of Environmental and Occupational Health, 67, 109116. http://dx.doi.org/10.1080/19338244.2011.598891

[29] Karunamoorthi, K. and Yirgalem, A. (2013) Insecticide Risk Indicators and Occupational Insecticidal Poisoning in Indoor Residual Spraying. Health Scope, 1, 166-173. http://dx.doi.org/10.5812/jhs.8344

[30] Potter, M.F. (2008) Bed Bug Supplement. The History of Bed Bug Management. Pest Control Technology, 36, S1.

[31] Busvine, J.E. (1958) Insecticide-Resistance in Bed-Bugs. Bulletin of World Health Organization, 19, 1041-1052.

[32] Douglas Reis, M. (2010) An Evaluation of Bed Bug (Cimex lectularius L.) Host Location and Aggregation Behavior. Master's Thesis, Virginia Polytechnic Institute and State University, Blacksburg.

[33] Adeyeye, A., Adams, A., Herring, L. and Currie, B.P. (2010) Bed Bug Infestation on a Maternity Unit in a Tertiary Care Center. American Journal of Infection Control, 3, E82. 


\section{Appendix 1. Jimma University College of Public Health and Medical Science Department of Environmental Health and Technology}

\section{Questionnaire}

\section{PERSONAL INFORMATION OF STUDY PARTICIPANT}

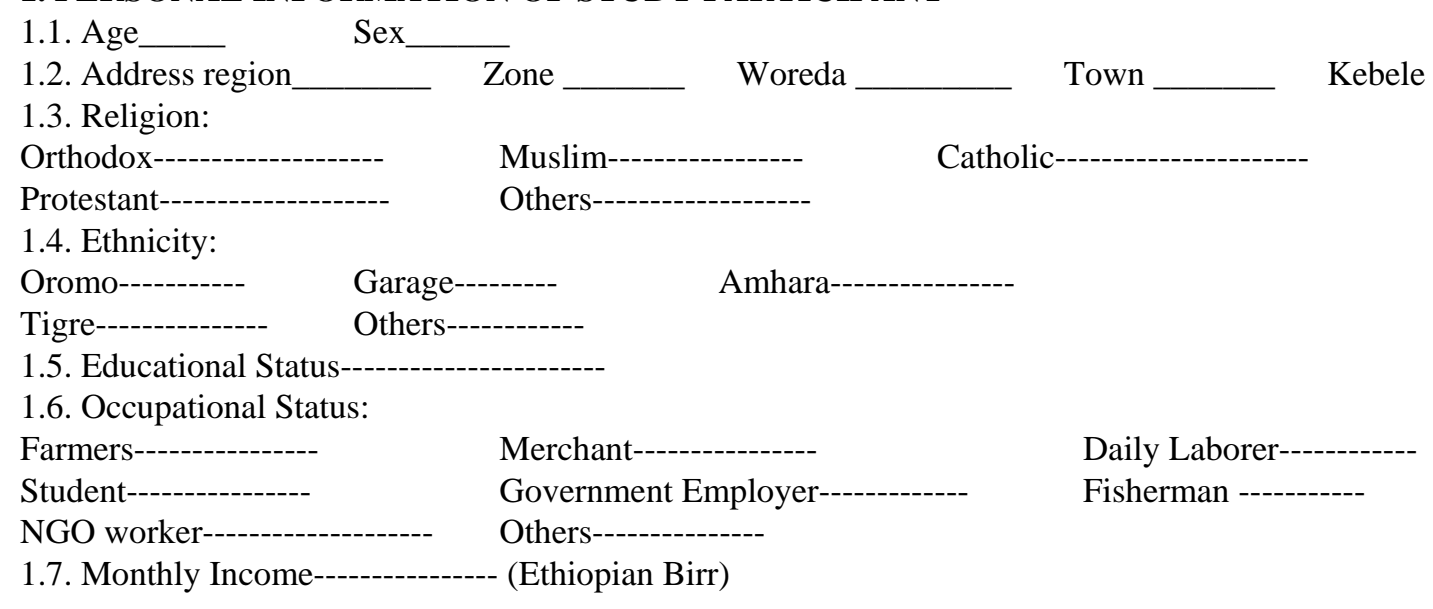

\section{RELEVANT INFORMATION}

2.1. Type of wall of the house:

Mud------- ConcreteOthers (specify) ---------------

Is there any crack and crevices on the wall?

Yes-------- No-------

2.2. Type of the floor:

Mud------ $\quad$ Concrete------------ $\quad$ Wood----------- $\quad$ Others (specify) ---------

Is the floor dusty?

Yes----- No------

Are there any cracks on the floor?

Yes--- No------

2.3. Type of roof:

Corrugated iron sheet-

Hatched----------- $\quad$ Others (specify)

2.4. Type of bed and bed frames:

Wood---------- Metal-------- $\quad$ Others (specify)

Are there any cracks and crevices on the bed and bed frames?

Yes----- No-----

2.5. Total number of rooms or partitions of the main house----------------

2.6. What is the total number of people live in each room?

\section{ASSESSMENT OF KNOWLEDGE OF RESIDENTS TOWARDS BEDBUGS}

3.1. Are there bedbugs in your house?

Yes----- No-------

3.2. If yes, $\mathrm{Q}_{3.1}$ do you know way of transmission?

Yes----- No--------

3.3. If yes, $\mathrm{Q}_{3.2}$ how does it be transmitted from person to person?

Yes----- No-----

3.4. Do you know how to prevent or control bedbugs?

Yes----- No-------

3.5. If yes, $\mathrm{Q}_{3.4}$ how can it be prevented?

Using traditional methods-

Using drugs

By washing clothes

Using exposing to sunlight- 
Others (specify)

3.7. Do you have any information about bedbugs?

Yes----- No-------

3.8. If yes, $\mathrm{Q}_{3.7}$ Where do you get treatment?

Health center's.

Hospitals.

Health status..........

Community health.

Others (specify).........

3.9. Do you know the risk of bed bugs?

Yes........... No.........

3.10. If yes $Q_{3.9}$ would you tell me what they are?

Skin rash

Body itching............

Nervous illness..........

Anxiety. ....

Leopard skin....

Body swelling.

Others (specify)

3.11. Does the bedbugs have a role in the transmission of diseases?

Yes.......... No........

3.12. If yes, would you mention some of diseases that the bedbugs hold for their transmission?
1.
3.$$
2 .
$$

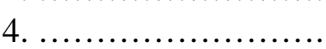
5.
6.

3.13. Do you know how the bedbugs multiply?

1. They lay eggs...

2. They directly give birth.

3. Others (specify).

4. I don't know

\section{ATTITUDES}

4.1. Do you feel/worried discomfort due to presence of bedbugs in your houses?

Yes................. No..................
4.2. If yes, in what sense you feel discomfort due to their presences?

a. They have a bad odor

b. Their bite is painful

c. Their presence is disgusting

d. They transmit diseases or act as vector

e. They causes diseases themselves

f. They annoy people

g. They have social stigma

h. Others (specify)

4.3. Do you feel discomfort due to control of bedbugs when using local modern methods practice? Yes...... No.........

4.4. If yes, $\mathrm{Q}_{4.3}$ In what cases.

\section{PRACTICES}

5.1. Do you know how to control the bed bugs?

Yes......... No........

5.2. Do you have a practice of washing your clothes regularly?

Yes......... No. No.

5.3. Did you practice any vector control around in your residential house?

Yes......... No.........

5.4. Have you advised your family and your neighbors' to keep personal hygiene and houses clean?

Yes......... No........

5.5. Have you used repellant plants to avoid bedbugs?

Yes........ No........

5.6. If yes, Q5.5 Name the plants....

5.7. If it is applicable, how it is applicable? 
Smoke Keeping the plant in the room

Spray or inside the house Others (specify)

5.8. Application time. Morning.....

Evening.

Night.

Midday

Others (specify)

5.9. Which plant is more effective and its methods of application

Name of the plant

Application Method

5.10. How many times do you apply in a day?

Once times a day.............. Two times a day

Three times a day................ Others (specify)

5.11. Modern methods to control bedbugs (Types of insecticides)

5.12. Frequency of the insecticide usage.

Six months

Within six-month

One year.

Two year.

Three year.....

Others

5.13. From the local/ traditional/or modern methods, which one is your preferences?

Why you prefer this method?

5.14. What are the environmental control methods you practices so as to control bedbugs?

a. Keeping personal hygiene.

b. Washing the clothes frequently.....

c. Manage wastes in the houses in a safe way....

d. Cracks and crevices in the house plugging.

e. Avoid sharing of clothes

f. Pouring boiling water over beds and bed frames.

g. Taking all the above.

h. Others

\section{PREVALENCE}

6.1. Are bedbugs present in your houses? (in any rooms/partitions)

Yes....... No.......

6.2. if yes, Q6.1

a) In how many of total rooms are bedbugs prevalent?

b) Are bedbugs also prevalent in the kitchen? (have you ever noticed any on floor, on wall, on the roof, Yes...

No.

c) Are bedbugs also prevalent in the main house?

Yes

No.

d) In which room in the houses do you frequently observe?

6.3 Are there any signs of presence of bedbugs in the house?

Yes........ No...............

6.4 If yes. Q6.3 which sigs

a) live bedbugs seen.

b) Dead bedbugs' body seen

c) Egg/egg shell of the bed bugs seen

6.5 If you see eggs of the bed bugs, which is the shape of it?

Circular.

Cylindrical

Oval.

Others (specify).

\section{Appendix 2}

\section{Observational Checklist}

1. Personal hygiene of the residential households

Good

Fair.

Poor. 
2. Standards of the residential houses

Good ............. Fair.............. Poor

3. Environmental safety around the house is acceptable?

Yes

$$
\text { No. }
$$

4. Are there any cracks crevices, dusts and other wastes in the houses?

Yes.....

of bedbugs in the houses.

5. Checking the presences

Presences of bedbugs

Where it is observed?

a. Live bedbugs

b. Dead bedbug

c. Egg/egg shell

6. Are there any insects which are related to the presences of bedbugs?

Yes......

No.

If yes, what type of insects?

Thank you for your kind cooperation 